\title{
Java Programming Language Learning Application Based on Octalysis Gamification Framework
}

\author{
Leon Christopher ${ }^{1}$, Alexander Waworuntu ${ }^{2}$ \\ ${ }^{1,2}$ Department of Informatics, Universitas Multimedia Nusantara, Tangerang, Indonesia \\ ${ }^{1}$ leon.christoper@student.umn.ac.id, ${ }^{2}$ alex.wawo@umn.ac.id
}

Accepted on May 19, 2021

Approved on June 09, 2021

\begin{abstract}
Java programming language is rated as the second most active language in the world based on GitHub active repository statistic. Meanwhile, many university students are found lack interest to learn Java. Many researches have shown the positive impact of gamification in many areas of life, include education and learning. The purpose of this study is to design and build an application to learn java programming language with gamification in mind. We use Octalysis Gamification Framework to design the usage of game mechanics in the application. The application was tested on second year students to learn Java for the first half semester and evaluated using the Unified Theory of Acceptance and Use of Technology (UTAUT) Model and get the result of $74.27 \%$ agree that the application is well accepted by the students.
\end{abstract}

Index Terms-gamification; java programming language; octalysis gamification framework

\section{INTRODUCTION}

Java programming language is a high-level objectoriented programming language that allows its developers to write a write once, run anywhere (WORA) code [1]. Based on data from GitHut.info, Java programming language ranks second after JavaScript as the most active programming language on the GitHub repository (Fig. 1). Java programming language is also widely used at higher education to learn object-oriented programming concept [2][3]. While Java is one of the most widely used programming language and is included in the higher education curriculum, from a student's point of view, there are several difficulties in learning, one of which is the lack of interest in learning Java [4].

Gamification has been used as a way to change people's behavior in various fields, such as health [5], social [6], economy [7] and education [8][9]. Many studies have been conducted and found that gamification can be used as a way to increase student motivation, engagement and achievement [9]. In other study, it was also found that the use of gamification, especially in learning programming language can increase effectiveness and enhance student understanding [10]. The main objective of gamification is not making computer games, but rather implementing game elements, such as challenges and feed back in the learning process [11]. The Application of gamification can be done directly by the instructor in the class [12] or through an application (desktop, web or mobile) [13].

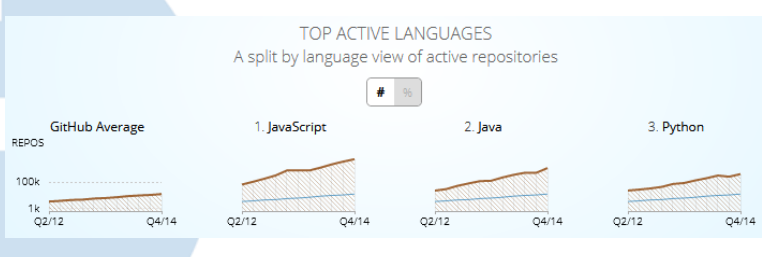

Fig. 1. Active repository by programming language on GitHub Source: GitHug.info [accessed: 19 June 2020]

Octalysis Framework is a gamification design approach introduced by Yu-Kai Chou [14], which has often been adopted to design gamified systems [15], including gamification of learning systems [16][17][18]. The aim of this study is to design and develop a mobile application to motivate, engage and help students learn Java programming language in an interesting way with gamification designed with Octalysis Gamification Framework. To evaluate the resulting application, we use UTAUT model which has proven to be a practical reference for designing mobile learning systems [19].

\section{GAMIFICATION DESIGN}

Octalysis is a gamification design framework introduced by $\mathrm{Yu}$-kai Chou, on his way to discover how gamification can improve life in various aspects. Chou found that the most successful games had core drives that triggered them to make decisions and carry out activities [14]. These core drives are called octalysis framework. Octalysis comes from the octagon from which represents 8 main human core drives which drives their motivation to act desired behavior (Fig. 2). We will design the gamification of our application based on this 8 core drives. 


\section{ISSN 2355-0082}

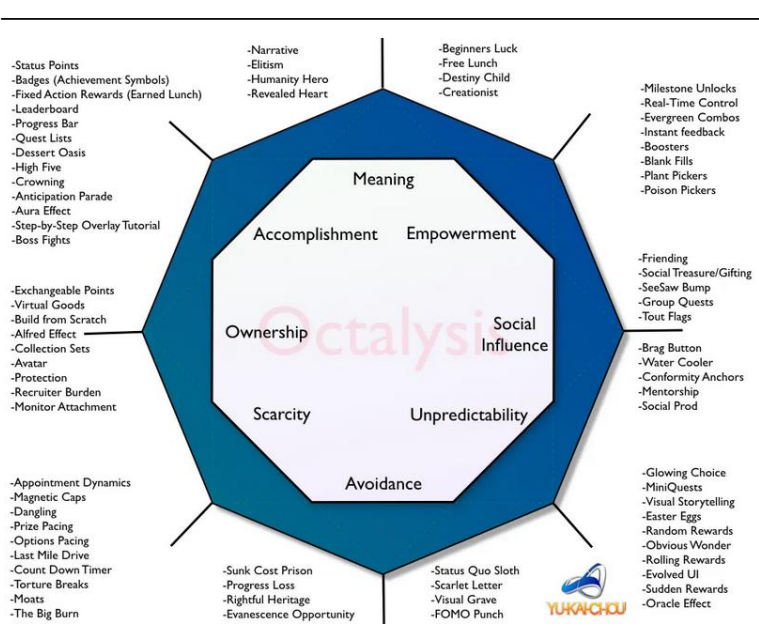

Fig. 2. Octalysis gamification framework

\section{A. Core Drive 1: Epic Meaning \& Calling}

This core drive is about selfless acts which drive people to do something bigger than themselves because they feel they are chosen, even though there is no reward guarantee. In the stages of learning Java programming language, we provide a narrative to the user about a programmer who is struggling to solve a pandemic problem, where he has to solve a various kinds of code questions to get a vaccine. This implies that by learning Java, user can make a good contribution to the world.

\section{B. Core Drive 2: Development \& Accomplishment}

Points, Badges, and Leaderboard (PBLs) activities mostly use this core drive. It triggers internal drive of people to always make development which lead to a commitment to gain more skills in order to accomplish goals. Challenge is the main point, without challenge, any reward got by someone will be meaningless. Development and accomplishment core drive is implemented using Status Points, Leaderboard and Quest. Points are obtained after completing several questions from each level, these points will be displayed on the Leaderboard screen which displays the users' rank based on points. Points also can be used as exchangeable points to be exchanged for virtual goods. Quest's screen will display quest list that the user can complete to get the prizes that has been determined. This quest list is divided into two, namely daily quest that can be repeated everyday and quest that can only be completed once. By completing the mission in this quest list, user can get prizes in the form of points, and/or virtual goods.

\section{Core Drive 3: Empowerment of Creativity \& Feedback}

This core drive focuses on creative activity which repeatedly done by someone to find out other combination in something followed by feedback given from others to improve his result. Milestone unlocks are used to trigger the core drive of empowerment of creativity and feedback. Milestone unlock is a stage that opens after the user complete certain levels. This new stage has a more complicated difficulty level than the previous stage.

\section{Core Drive 4: Owenership \& Possession}

This core drive comes up when people feel that they own something to control and triggered the eagerness to improve it. Gamification elements used in core drive ownership \& possession are virtual goods and avatar. Virtual goods are goods or items in the form of virtual technology gears that can be purchased from the shop screen. Any virtual goods acquired by the user will be displayed in the user avatar to increase the user pride.

\section{E. Core Drive 5: Social Influence \& Relatedness}

This core drive cover all social elements that motivate people, including mentorship, acceptance by society, feedback from peers, companionship, competition and envy. Core drive social influence and relatedness is implemented through friending and social treasure. Friending is a friendship system that is implemented in the application where user can establish friendship with other users. Social treasure allows connected users to help each other by giving points or help with the code problems.

\section{F. Core Drive 6: Scarcity \& Impatience}

Most people want something that is rare, exclusive or not immediately attainable. This is the idea behind scarcity \& impatience core drive. Implementation of core drive scarcity and impatience is done using Magnetic Caps, Prize Pacing and Countdown Timer. Magnetic Caps is used to limit the use of hints for each given question. Prize Pacing is prizes that are obtained after completing each level with an amount that is adjusted to the user's current level. The count down timer is set each the user answer a question, and the remaining time available determines the amount of bonus that the user can get.

\section{G. $\quad$ Core Drive 7: Unpredictability \& Curiosity}

This drive comes up when people don't know what will happen next. When something going out of their regular pattern, they tend to pays attention to the unexpected. Core drive unpredictability and curiosity applies the Random Rewards gamification element, where the user will get random rewards on daily login. 


\section{H. Core Drive 8: Loss \& Avoidance}

This core drive is about motivation to avoid something negative from happening. This could be to avoid losing previous work. Core drive loss and avoidance applies the gamification element of Progress Loss. It is used by reducing the user's progress if the user does not use the application for learning for a certain period of time.

\section{RESULTS AND DISCUSSION}

The Java programming language learning application was built using ReactNative and uses Firebase to store user data. The final result of the application is an Android mobile application. To use the application, user must register or login first. Fig. 3 shows the home screen after the user as logged into the application. At the top of the home screen, there is information on the points and hints count owned by the user. At the top left, there is a menu for Quest, Profile and Notification. At the bottom, there are Shop, Avatar, Home, Friends and Leaderboard tabs.

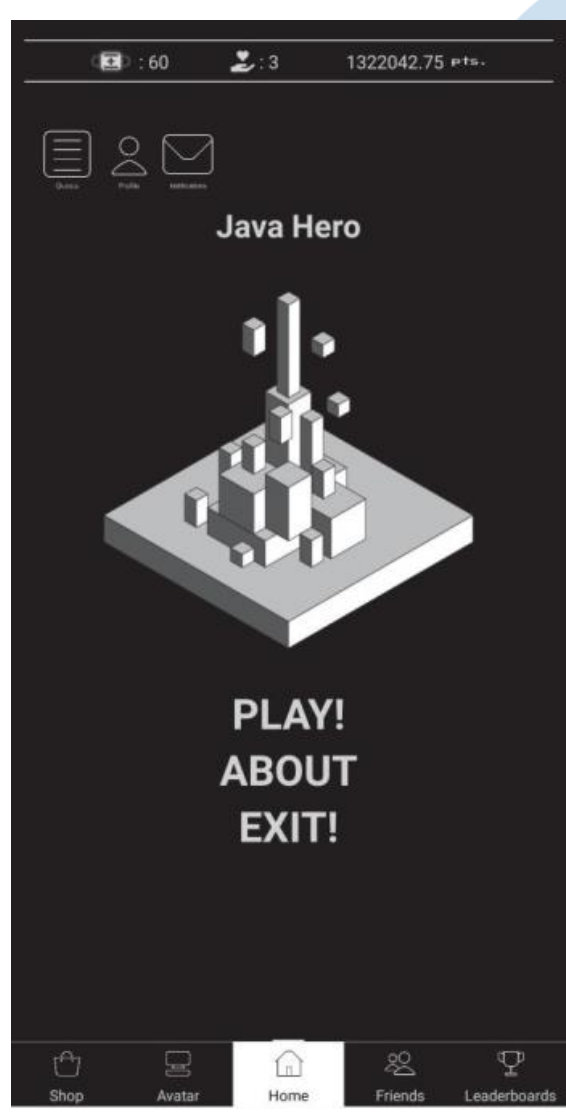

Fig. 3. Home screen

The user start learning by entering the gameplay, the user will get a question in the form of incomplete source code. Users will be asked to enter the answer in the available blank fields. Users can also ask for hints or instruction regarding the answer by tapping the user character on the bottom left (Fig. 4). When the user has finished answering questions, a modal window will appear showing the result and the prize that will be given to the user. The yellow star at the top of the modal window shows how many questions have been answered correctly. Finish time is the time used to solve questions, the score is the final result and the item and points obtained. Each question will be reviewed again by comparing the answer inputted by the user with the correct answer from the source code.

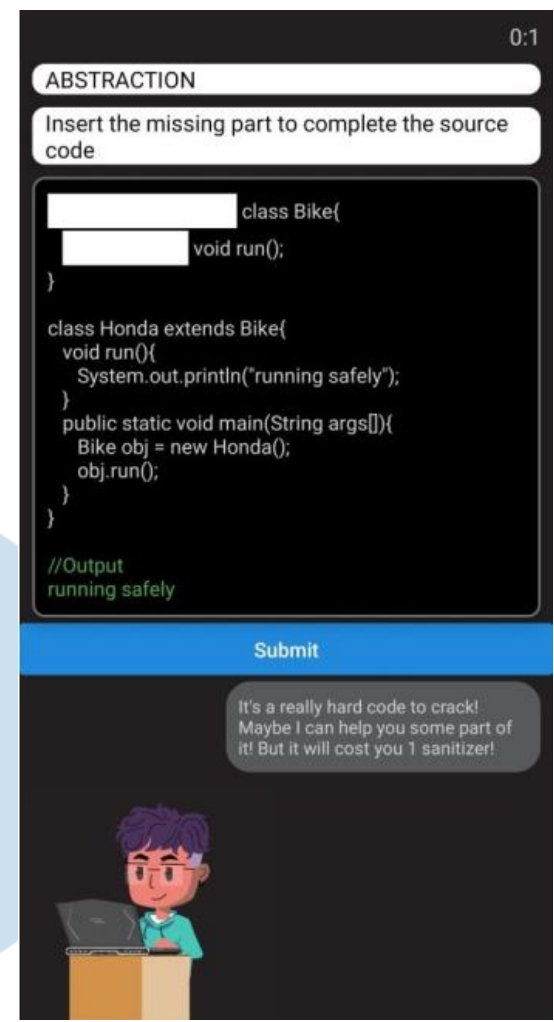

Fig. 4. Gameplay screen

When user select the Quest menu, a modal window will be displayed with two quest options, Daily Quest and Quest. When the user successfully completes a quest, he will get a reward according to the mission completed. Fig. 5 is a profile screen that displays user data, such as points, hints count, number of avatars, friends, and completed levels. 


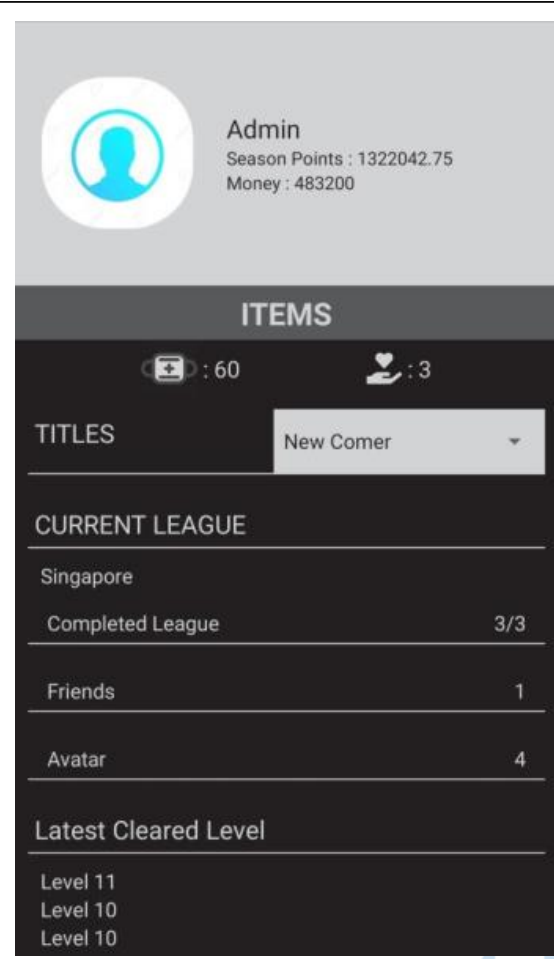

Fig. 5. Profile screen

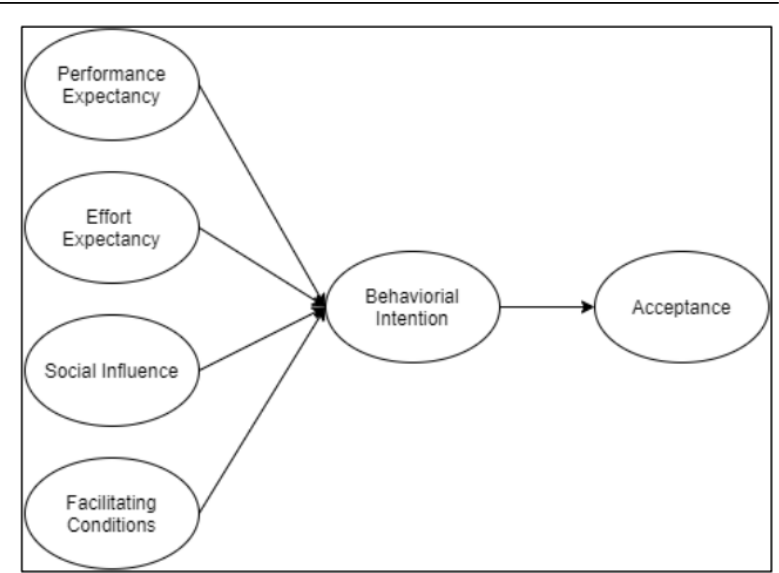

Fig. 6. Simplified UTAUT model

The questionnaire was given to $402^{\text {nd }}$ year students who were taking object-oriented programming course after using gamified Java learning application for half a semester. Table I shows the results of the Likert scale calculation for the questionnaire responses collected based on factors from the UTAUT model. The result shows that the gamified application for learning Java programming is successful and well accepted by the respondents.

TABLE I. LIKERT SCALE RESUlT FROM UTAUT MODEL user can acquire by exchanging their points, while the Avatar Screen displays the avatar and virtual goods the user already has. Friends screen displays list of friends the user has along with summary information about them, such as points and levels. The Leaderboard displays the order of users based on points who are actively using the application to learn Java for the past 30 days.

\section{TESTING AND EVAluAtions}

The application was tested using questionnaire following the Unified Theory of Acceptance and Use of Technology (UTAUT) model. UTAUT model is an integrated model introduced by Venkatesh et al based on social cognitive theory with a combination of eight leading research models regarding the acceptance of information technology [20]. This study uses a simplified version of the UTAUT model that uses indicators of Performance Expectancy, Effort Expectancy, Social Influence, Facilitating Conditions, and Behavioral Intentions (Fig. 6).

\begin{tabular}{|l|c|c|}
\hline \multicolumn{1}{|c|}{ UTAUT Factor } & Result & $\begin{array}{c}\text { Percentage and } \\
\text { Interpretation }\end{array}$ \\
\hline $\begin{array}{l}\text { Performance } \\
\text { Expectancy }\end{array}$ & 0.7675 & $76.75 \%$ (Agree) \\
\hline Effort Expectancy & 0.776 & $77.6 \%$ (Agree) \\
\hline Social Influence & 0.66 & $66 \%$ (Agree) \\
\hline Facilitating Conditions & 0.76 & $76 \%$ (Agree) \\
\hline Behavioral Intentions & 0.75 & $75 \%$ (Agree) \\
\hline
\end{tabular}

The results of the user acceptance test were successful, but if we look closely, it can be seen that Social Influence got the lowest score on the Likert scale. We conducted interviews with the respondents to analyze the result further and found that this application is not yet well known. So, the use of gamification may increase motivation and interest to learn Java, but the application itself is not widely known, which is not the main goal of this study.

\section{CONCLUSION AND FUTURE WORKS}

In this study, we have design and develop a gamified Java learning application to improve students' interest and motivation in learning Java programming language. The framework that was used is Octalysis Gamification Framework by Yu-kai Chou. We carried out a user acceptance test following the UTAUT model with an average Likert scale calculation result of $74.27 \%$, which meansthat the Java learning application with gamification was well accepted by users.. For future study, we are planning to experiment and analyze each core drive in the 
Octalysis Framework to find out which drive give the most impact on the students' behavior in learning programming language.

\section{REFERENCES}

[1] C. Horstmann, Big Java: Early Objects, 7th ed. NJ: John Wiley \& Sons, 2019.

[2] Y. Ren and S. Ji, "A Study of Teaching International Students Java Programming at Shanghai Dianji University," Int. J. Sci., vol. 8, no. 3, pp. 71-74, 2021.

[3] R. Z. Cabada, M. L. B. Estrada, F. G. Hernández, R. O Bustillos, and C. A. Reyes-García, "An Affective and Web 3.0-Based Learning Environment for a Programming Language," Telemat. Informatics, vol. 35, no. 3, pp. 611-628, 2018, doi: 10.1016/j.tele.2017.03.005.

[4] M. Sivasakthi and R. Rajendran, "Learning difficulties of 'object-oriented programming paradigm using Java': Students' perspective," Indian J. Sci. Technol., vol. 4, no. 8, pp. 983-985, 2011, doi: 10.17485/ijst/2011/v4i8/30906.

[5] D. Lie, J. C. Young, and S. Hansun, "Dietary application for diabetic patients using gamification method," Int. J. Sci. Technol. Res., vol. 9, no. 4, pp. 2417-2423, 2020.

[6] D. Bianchini, D. Fogli, and D. Ragazzi, "Promoting citizen participation through gamification," ACM Int. Conf. Proceeding Ser., vol. 23-27-Octo, 2016, doi: 10.1145/2971485.2971543

[7] E. Siswanto, "Increasing the Customer Loyalty in ECommerce By Using Gamification Strategy: Case Study for Indonesia Customers," Innovativeresearchpublication.Com, no. July, p. 9788193137345, 2016, [Online]. Available: http://www.innovativeresearchpublication.com/documents/pa pers/july2016pattaya/pdf 12.pdf.

[8] C. Sinly, A. Rusli, and P. M. Winarno, "Utilizing gamification to improve user participation in online judge," Proc. - 2018 Jt. 10th Int. Conf. Soft Comput. Intell. Syst. 19th Int. Symp. Adv. Intell. Syst. SCIS-ISIS 2018, pp. 543-547, 2018, doi: 10.1109/SCIS-ISIS.2018.00096.

[9] F. Pradana, F. A. Bachtiar, and B. Priyambadha, "Pengaruh Elemen Gamification Terhadap Hasil Belajar Siswa Pada ELearning Pemrograman Java," in Seminar Nasional Teknologi Informasi dan Multimedia, 2018, no. February, pp. 7-12.

[10] F. L. Khaleel, N. S. Ashaari, T. S. Meriam, T. Wook, and A. Ismail, "The study of gamification application architecture for programming language course," ACM IMCOM 2015 - Proc., 2015, doi: 10.1145/2701126.2701222.

[11] A. R. Yohannis, Y. D. Prabowo, and A. Waworuntu, "Defining gamification: From lexical meaning and process viewpoint towards a gameful reality," in 2014 International Conference on Information Technology Systems and Innovation, ICITSI 2014 - Proceedings, 2014, pp. 284-289, doi: 10.1109/ICITSI.2014.7048279.

[12] T. Sulispera and M. Recard, "Octalysis Gamification Framework for Enhancing Students' Engagement in Language Learning," Dialekt. J. Pendidik. Bhs. Ingg., vol. 8, no. 2, pp. 103-128, 2021

[13] C. Hursen and C. Bas, "Use of gamification applications in science education," Int. J. Emerg. Technol. Learn., vol. 14, no. 1, pp. 4-23, 2019, doi: 10.3991/ijet.v14i01.8894.

[14] Y.-K. Chou, Actionable Gamification: Beyond Points, Badges, and Leaderboards. 2016.

[15] A. Mora, D. Riera, C. Gonzalez, and J. Arnedo-Moreno, "A Literature Review of Gamification Design Frameworks," VSGames 2015 - 7th Int. Conf. Games Virtual Worlds Serious Appl., 2015, doi: 10.1109/VS-GAMES.2015.7295760.

[16] B. Göschlberger and P. A. Bruck, "Gamification in Mobile and Workplace Integrated MicroLearning," in ACM International Conference Proceeding Series, 2017, pp. 545552, doi: 10.1145/3151759.3151795. a Community College Setting," J. Educ., vol. 199, no. 2, pp. 83-88, 2019, doi: 10.1177/0022057419848371.

[18] S. A. A. Freitas, A. R. T. Lacerda, P. M. R. O. Calado, T. S Lima, and E. D. Canedo, "Gamification in Education: A Methodology to Identify Student's Profile," in Proceedings Frontiers in Education Conference, FIE, 2017, vol. $2017-$ Octob, pp. 1-8, doi: 10.1109/FIE.2017.8190499.

[19] C.-M. Chao, "Factors determining the behavioral intention to use mobile learning: An application and extension of the UTAUT model," Front. Psychol., vol. 10, no. JULY, pp. 114, 2019, doi: 10.3389/fpsyg.2019.01652.

[20] V. Venkatesh, M. G. Morris, G. B. Davis, and F. D. Davis, "User Acceptance of Information Technology: Toward a Unified View," MIS Q., vol. 27, no. 3, pp. 425-478, 2003, [Online]. Available: 